\title{
Enfrentamentos em torno de gênero Resistências em defesa da diversidade nas escolas
}

\section{Confrontations around gender}

Resistence in defense of diversity in schools

\section{Enfrentamientos alrededor del género}

Resistencias en defensa de la diversidad en las escuelas

\section{FÁTIMA WEISS DE JESUS}

Universidade Federal do Amazonas, Manaus- AM, Brasil.

\section{RAMILY FROTA PANTOJA ${ }^{* *}$}

Universidade Federal do Amazonas, Manaus- AM, Brasil.

\begin{abstract}
RESUMO: $\mathrm{O}$ artigo apresenta e discute, a partir de Manaus, o engajamento de pessoas ativistas/militantes LGBT e professoras/es antropólogas/es e de outras áreas interessadas/es no campo de gênero na reação à retirada de gênero nos textos dos planos municipal e estadual de educação e na criação de um grupo/movimento para contestar a Lei Municipal no 439/2017: o Educação pela Diversidade no Amazonas (Ediversa). Da mesma forma, procuramos compreender como categorias de entendimento são apropriadas, acionadas e reconstituídas no campo político e como acontece o enfrentamento das posições de tal campo a partir de teorias de gênero e sexualidade e suas apropriações em torno dos direitos humanos em gênero e sexualidade, ou seja, resistências.
\end{abstract}

Palavras-chave: Gênero. Educação. Política. Resistências.

* É Mestra e Doutora em Antropologia Social pela Universidade Federal de Santa Catarina. Atualmente é Professora da Universidade Federal do Amazonas e Coordenadora do Grupo de Estudos e Pesquisas em Gênero, Sexualidades e Interseccionalidades (GESECS). E-mail: <fatimaweiss@gmail.com>.

** É graduada em História pela Universidade Federal do Amazonas, mesma instituição na qual atualmente é Mestranda em Antropologia Social. Participa do Grupo de Estudos e Pesquisas em Gênero, Sexualidades e Interseccionalidades (GESECS). E-mail: <ramilyfrota@hotmail.com>. 


\begin{abstract}
This article introduces, and discusses, from Manaus, the engagement of LGBT activists, teachers, Anthropologists, and educators from different areas interested in the gender field studies, and their reaction to the withdrawal of gender based content from texts in the municipal, and state, educational plans; and also the uprising of a movement to contradict State Law № 439/2017: Diversity Education in Amazonas (Ediversa). Likewise, we have seeked to comprehend how categories of understanding are appropriate, activated, and reconstituted inside the political field. And how the confronting practices, of such a field, happen starting from gender and sexuality theories, and their appropriations surrounding human rights, regarding gender and sexuality, that is, as a means of resistance.

Keywords: Gender. Education. Politics. Resistance.
\end{abstract}

RESUMEN: El artículo presenta y discute, desde Manaos, la participación de activistas/militantes LGBT y maestras/os, antropólogas/os y de otras áreas interesadas/os en el campo de género como reacción a la retirada de género en los textos de los planes de educación municipales y de los estados y la creación de un grupo/movimiento para contestar la Ley Municipal No. 439/2017: el Educación para la Diversidad en Amazonas (Ediversa). Así que buscamos comprender cómo las categorías de comprensión son apropiadas, activadas y reconstituidas en el campo político y cómo se enfrentan las posiciones de este campo en función de las teorías de género y sexualidad y sus apropiaciones en torno a los derechos humanos en género y sexualidad, es decir, resistencias. Palabras clave: Género. Educación. Política. Resistencias.

\title{
Introdução
}

P artindo da concepção do trabalho antropológico, reflexão acadêmica e militância LGBT, Sérgio Carrara insiste que são fluidas as fronteiras entre o ativismo LGBT-militância e a reflexão acadêmica-pesquisa. Com isso, além de ter uma visão geral sobre as articulações entre ciência e política, aponta como se dá o conhecimento antropológico acerca desses temas e a importância do antropólogo nesse processo, que, para o autor, vem a ser a cidadanização da homossexualidade. Ora o autor utiliza e reduz ao termo "homossexualidade", mas também coloca que ele pode ser traduzido como "sexualidade e expressões de gênero não normativas", sob o argumento da fuga 
de um viés médico e da aproximação das identidades que se colocam politicamente sob a sigla LGBT (CARRARA, 2016).

Consideramos a articulação entre os estudos de gênero, feminismo e as ciências o caminho necessário para uma ciência com caráter emancipatório, como assinala Marlise Matos, por considerar toda uma trajetória do que veio a ser o estudo de gênero como proposta teórico-conceitual.

\begin{abstract}
Através de significados e re-significações produzidos e compartilhados na nova perspectiva analítica e que transversalizam dimensões de classe, etárias, raciais e sexuais, gênero tem tido papel fundamental nas ciências humanas de denunciar e desmascarar ainda as estruturas modernas de muita opressão colonial, econômica, geracional, racista e sexista, que operam há séculos em espacialidades (espaços) e temporalidades (tempo) distintas de realidade e condição humanas (MATOS, 2008, p. 336).
\end{abstract}

O campo dos estudos de gênero tem legitimidade e grande potencial de mudança não somente para a ciência em si, mas para toda a sociedade, que é composta de todas as diferenças, muito embora essas diferenças tenham sido alvo de homogeneização e silenciamento. Vale lembrar que podemos observar diferentes concepções e diversas problemáticas, ocasionando "profunda polifonia e a enorme riqueza embutida nessa arena de debates" (MATOS, 2008, 339). Acompanhando as discussões da autora, chama a atenção o fato de que embora possamos nos encontrar em um campo consolidado, não acreditamos que está tudo realizado, haja vista os ataques que temos sofrido como pesquisadoras/es do campo ou lecionando na rede básica de ensino, quando deparamos com a retirada do termo "gênero" dos planos de educação e enfrentamos leis que impedem discussões em sala de aula, no caso de Manaus, uma lei municipal.

Este artigo apresenta e discute o engajamento de pessoas militantes LGBT e professoras/es antropólogas e de outras áreas interessadas no campo em reação à retirada do gênero nos textos dos planos municipal e estadual de educação e na criação de um grupo/movimento para contestar a Lei Municipal no 439/2017: o Educação pela Diversidade no Amazonas (Ediversa).

É importante destacar que no estado do Amazonas, o Plano Estadual de Educação (PEE) entrou em discussão em junho de 2015, na Assembleia Legislativa do Amazonas (Aleam), e nessa ocasião todas as menções ao termo "gênero" foram substituídas por termos como "respeito à diversidade". Em sua capital, Manaus, o Plano Municipal de Educação teve, em 22 de junho de 2015, uma assembleia extraordinária para análise das emendas, quando não foi permitida a entrada de setores organizados, integrados por militantes LGBT, estudantes e professoras/es. Por outro lado, grupos religiosos estavam presentes e ambos estavam dispostos na galeria do prédio da Câmara Municipal de Manaus com cartazes. As palavras de ordem ouvidas de militantes entremeavam-se a orações dos grupos religiosos, não ficando de fora palavras de insulto. Apenas três vereadores se opuseram às emendas que retiravam gênero do PME. 
FL é professora na Universidade Federal do Amazonas, pesquisadora do campo de gênero, e foi uma das articuladoras do grupo que foi para a Câmara Municipal de Manaus, posteriormente Assembleia Legislativa; é também uma das fundadoras do Ediversa, ao lado de outras professoras e professores, estudantes e militantes dos direitos LGBT e nos concedeu entrevista para a realização da pesquisa ${ }^{1}$.

Quando FL começou a acompanhar as discussões, elas já tratavam da retirada de gênero do plano municipal, mas, em conversa com técnicas da Secretaria Municipal de Educação (Semed), ela soube que haviam acontecido, antes, outras reuniões para debate do plano. A presença dos/as estudantes foi significativa em seu relato, ela lembra que foi com quem conviveu posteriormente, e deixa isso explícito quando lembra de terem conseguido na Câmara interromper as discussões e ter acesso ao documento discutido para articular com alguns parlamentares a permanência de gênero no Plano Municipal de Educação: “Entrou a galera que já trabalhava na educação, entraram esses mais jovens, porque eram as referências LGBT que estavam lá e daí assim a gente debateu, debateu, debateu..."

Além da retirada de gênero, a reunião pautava a retirada de diversidade, segundo FL. Com efeito, a professora considerou que tal retirada implicava também a questão da diversidade religiosa, e para o dia, além de entrar em contato com movimentos de mulheres, entrou em contato com o movimento negro, a fim construir apoios e fortalecer o movimento de contestação que percebia necessário. Esse tema também aparece na fala de $\mathrm{MI}^{2}$, que, por sua vez, reclama a ausência de professores/as que pesquisam tal tema na universidade. Em sua reflexão, ela lembra que nada do que pensamos estar garantido (referindo-se a Lei 10639/20033) realmente está - sobretudo no período em que vivemos. Esse estado de alerta também lhes ocorreu, por perceber os ataques pelo País inteiro e sentir a necessidade de agir no âmbito estadual e municipal nos quais se encontravam inseridas aquelas pessoas.

Até aquele momento a professora não havia sequer ouvido a expressão "ideologia de gênero", ela diz que esteve na sessão porque sabia que era uma tentativa de tirar "gênero" do plano municipal de educação. Mas isso logo deixaria de ser novidade para ser recorrente, e "ideologia de gênero" se tornou mote de uma intensa campanha contra a diversidade com o Projeto de Lei no 389/2015.

Desde a Assembleia Legislativa, FL, em grupo, buscava "defender um discurso mais científico", que foi sustentado, naquela situação, junto com colegas da psicologia, e mesmo quando pensa em se colocar no "campo do enfrentamento político", esclarecimento que fazia. Seus argumentos continham bases do campo da ciência e da legalidade, quando havia um esforço de lembrar o que as leis garantiam. Como FL lembra e conta em entrevista:

a partir de dezembro de 2015 a gente começou a se organizar de forma mais sistemática e aí a nossa preocupação era essa, era contrapor o projeto de lei, mas era também 
Era o Ediversa que estava trabalhando. Inicialmente, na formulação de textos, com articulação através do Whats App, alternando encontros presenciais, troca de documentos e dividindo diferentes frentes/grupos de trabalho dentro de um mesmo coletivo. Criado no final de 2015, é principalmente em 2016 que há mais trabalho. FL explica que o processo "vai sendo liderado e protagonizado por diferentes pessoas a todo momento" e reconhece "de longe, uma certa centralidade nos professores da universidade, mas o documento é muito mais amplo que esse engajamento dos professores".

Após todo o trabalho coletivo de produção de documentos, o movimento, em formato de ato político que contou com a presença de várias pessoas, protocolou no Ministério Público Federal o que havia produzido. As pessoas que participaram do ato eram diversos professores/as, estudantes e membros de movimentos sociais. Os documentos também foram protocolados no Ministério Público Estadual, Defensoria Pública e Câmara Municipal de Vereadores para os gabinetes de dois vereadores. O primeiro entrave veio quando perceberam, a partir das respostas aos documentos, e como informa FL, "que o Ministério Público só podia atuar depois de aprovada e sancionada a lei pelo prefeito". A lei, no entanto, foi aprovada somente no ano de 2017.

Nesse percurso, o grupo trabalhou para realizar eventos e discussões, rodas de conversa, e houve a apresentação de trabalho em eventos, pois o que se tinha eram documentos. E a escolha por documentos vem justamente pelo entendimento de que estavam lidando com leis; assim, era essencial que se tivesse um outro material que se apresentasse como base para a apreciação da lei. Nas palavras de FL, o "documento meticuloso que mobilizava aspectos da legislação, mobilizava teoria... os estudos de gênero... Mobilizava teorias da pedagogia, enfim, tinha essa preocupação". Embora isso não impedisse que cada membro continuasse e levasse os debates para espaços de militância que cada um possuía.

O debate científico e a produção de documentos foram imprescindíveis na composição de forças à situação vivida em Manaus. Antes do Ediversa, havia uma dispersão entre as pessoas engajadas no tema e multiplicadas vozes de pessoas que eram contra a retirada do gênero. Estas, por sua vez, apresentavam grave desconhecimento sobre $o$ tema. Eram muitas as pessoas e elas possuíam uma certa força até o momento; tal situação é colocada por MI, quando comenta sobre sua participação na CMM e lembra a força da oposição, uma vez que ela sequer contava que o grupo estivesse ali, pensando encontrar na Câmara somente pessoas a favor das discussões. Não demoraria para que ela percebesse uma oposição "muito forte", comparada ao grupo reduzido ao qual ela estava inserida e avaliava os dois primeiros dias do embate que se sucedeu, pois ele não terminou na CMM. 
Na CMM, porém, apesar de opostos, houve tentativa de diálogo por parte do grupo de alunos/as e professores/as com o grupo religioso, mas a tentativa não surtiu efeitos. No relato de MI, ela expõe a recusa do diálogo e, no caso de $\mathrm{TA}^{4}$, o diálogo partiu de um religioso que se dizia professor, o qual, além de versar sobre o conteúdo, também se interessava em saber a veracidade das informações que a estudante fornecia, do nível de embasamento teórico e científico que o grupo possuía. Algo que indigna MI pois ela enfatiza a importância de - e também o seu reconhecimento enquanto - educadores/as, professores/as e pesquisadores/as do tema:

Gente que não é da área de licenciatura, que não é da área da educação, que nãoé... não é professor. Um advogado falar... representantes do arcebispo ali dizer que não podia isso, saca? Então a gente já vê como a igreja tem uma forte influência na política do Amazonas, na política em si... sendo que o Estado é laico, né!?

Percebemos as expectativas e receios de profissionais também em tese de Érica Rotondano, a partir da fala de uma de suas interlocutoras, registrada em diário de campo:

Os educadores que deveriam ser os principais defensores da diversidade, se tornam seus maiores inimigos, na medida em que passam a acreditar que a degeneração humana e a desagregação familiar é culpa dos homossexuais (ROTONDANO, 2019, p. 122).

Há o esforço da Associação Brasileira de Antropologia (ABA) em divulgar notas e informativos em defesa das pautas em voga, através de seu Comitê Gênero e Sexualidade $^{5}$. A atuação da ABA, o engajamento de antropólogos/as em tais temas podem ser explicados a partir da discussão sobre o papel da antropologia no processo de cidadanização da homossexualidade (CARRARA, 2016) na qual o autor discute também uma negociação entre política e ciência, pois falamos de experiências que envolvem nossa teoria mas também de práticas políticas de outros sujeitos e, de acordo com o autor, seria um equívoco pensar que tais práticas são incompatíveis com as nossas ou, ainda, atribuir uma rigidez que não cabe entre nossa teoria e as experiências daquilo (daqueles/as) que estudamos. Ao contrário, essas negociações envolvem pessoas, ideias, linguagens, legitimações mútuas, além de conflitos e cooperações.

MI também se preocupa com a formação de pessoas que, teoricamente, teriam de estar ao nosso lado nesse enfrentamento; no entanto, se mostram contrárias, expressando argumentos já conhecidos, que visam a preservação do que acreditam ser a família natural: "tinha psicóloga, gente... tinha psicóloga que era da igreja falando que era errado que essa ideologia que a gente... que queria se implementar na educação ia destruir as crianças, que ia transformar as crianças, sabe!? Uma psicóloga falando isso?" Tais atitudes ocorrem, a despeito das orientações de seu conselho de classe ${ }^{6}$, praticadas por indivíduos orientados sobretudo por suas crenças e a defesa intransigente de seus privilégios 
nesta sociedade que busca a regulação da vida privada através do alcance de espaços para "garantir hegemonia no campo das políticas educacionais em sexualidade" (ROTONDANO, 2019, p. 100). Da mesma forma que MI se surpreende com a presença de profissionais da psicologia, FL também é surpreendida com a presença de professoras ou doutorandos/as que se identificavam como professoras da Faculdade de Educação da Ufam e estiveram na Assembleia Legislativa do Amazonas na discussão do plano estadual e se colocaram contra as questões de gênero pautadas.

Entendemos como é importante a presença e o espaço de pessoas com formação e/ ou experiência sobre as discussões colocadas; tais formações e experiências foram fundamentais para a formação do Educação pela Diversidade no Amazonas. Erica Rotondano afirma que "os participantes do grupo, [...] na ocasião, iam sendo incluídos por meio da indicação de outros, já adicionados, tendo como critério, estar vinculado ao trabalho, estudos, pesquisas na área" (2019, p. 99). A ocasião a que a autora se refere trata-se da primeira reunião presencial realizada pelo Ediversa. Para a autora, "o PL suscitou a organização de grupos de resistência”, constituídos pelos grupos já mencionados; a autora considera ainda a importância do Movimento Amazonas Contra Mordaça. Outros autores também têm apontado a articulação das pautas no cenário nacional com o movimento Escola Sem Partido.

Somando à importância de pessoas vinculadas ao meio acadêmico ou da educação básica, MI ressalta a sua importância enquanto estudante, mas travesti, tocando em pontos importantíssimos na defesa das discussões de gênero dos planos, como a evasão escolar: "eu digo isso que a escola é um lugar que discrimina e que fomenta a discriminação, fomenta a discriminação porque não tem esse tipo de... é difícil encontrar uma escola aqui que os professores tenham esse diálogo". Contudo, ela insiste na autonomia dos professores de abordar os assuntos na sala de aula, mas reconhece que, antes de tudo, muitos não o fazem por falta de interesse, além da falta de incentivo do Estado.

Por outro lado, sustenta a importância de tocar nesses assuntos e discuti-los, pois, os sujeitos estão presentes em sala de aula

como um grupo de meninos gays, eles... que tinha na sala, eles gostaram da aula porque eles desconhecem que há uma história da população LGBT, e é isso que eu acho que é uma das coisas que eu bato, eu discuto com... algumas vezes é que tem que se ter uma construção da trajetória dessas pessoas porque tem

ou em outro momento:

de alguma forma tem que manter a ligação, falar sobre homossexualidade, por exemplo, tem aluno gay dentro da sala de aula, mas esse assunto sobre homoss... não é pra discutir com o aluno gay, é pra discutir com todos que não sabem como é a experiência de um aluno que é gay, o que sofre na pele, e isso tem que ser discutido. Mas a ideia que muitos têm é que discutir sobre homossexualidade, travestilidade, gênero e sexualidade é um problema que vai acarretar no que... no que a pessoa vai se transformar, entendeu? E não é assim! As pessoas pensam assim". 
Durante algum momento ela acredita que algumas pessoas estiveram como "massa de manobra". Perguntada sobre de quem seriam e ela responde que pela própria Igreja Católica, mas reconhece que "o grupo da Renovação Carismática seria um grupo... como eu posso dizer? Seria um grupo conservador dentro da Igreja Católica”. É preciso considerar que a Igreja Católica também tem um reduto mais conservador; em Manaus, a Renovação Carismática teve importante presença na votação do PME, além dos já mencionados evangélicos. Vale lembrar que tais setores compactuam contra o aborto, a ideia inclusiva de família e políticas de combate à homofobia (ROTONDANO, 2019:101).

Através dessa união por interesses em comum de distintos grupos religiosos, foi sancionada em Manaus a Lei Municipal nº 489/2017, proposta pelo vereador e pastor Marcel Alexandre, inicialmente como o PL 389/2015. O Projeto de Lei tomava como “ideologia de gênero" as discussões e trabalhos que envolvessem o campo dos estudos de gênero e demarcava como orientação política esse campo, tratando-o apenas como um "conceito" e definindo ideologia de gênero como "a ideologia, segundo a qual, os dois sexos, masculino e feminino, são considerados construções sociais e culturais" ${ }^{\prime 7}$.

O texto do projeto de lei é suscinto, contendo apenas dois artigos; é na justificativa do projeto que encontramos mais elementos para análise. Observamos como argumento a ausência do termo "ideologia de gênero" no Plano Nacional de Educação, discutido no ano anterior. Ora, nem poderia estar presente o termo, uma vez que ideologia de gênero sequer era considerado termo legítimo e de cunho científico para o nosso campo. Em seguida, o autor do PL, Marcel Alexandre, utiliza e reconhece que "o termo gênero" é que esteve ausente do plano nacional. Vale lembrar que essa suposta confusão de nomenclaturas também é sustentada para confundir os apoiadores, quando não sabem explicar o que seria a "ideologia de gênero" e/ou resumem a definição apresentada no Art. $1^{\circ}$ do PL. Tal confusão e a falta de argumento entre os apoiadores é percebida no relato de pessoas que estiveram na Câmara Municipal de Manaus e Assembleia Legislativa durante os debates sobre o assunto.

O projeto, apesar de todos os equívocos e inconsistências, se tornaria lei sancionada dois anos depois, mas resgatamos enquanto PL, pois foi a partir daí que as pessoas que se encontraram nas discussões dos planos de educação iniciaram um outro momento de intensa mobilização. De acordo com Érica Rotondano (2019), o PL provocou a formação do grupo de resistência Ediversa. A atuação do Ediversa, os interesses e perspectivas individuais e coletivas de seus membros conduziram às ações concretas do movimento, algumas já destacadas aqui.

O projeto de lei, na sua justificativa, argumentava que o Plano Nacional de Educação retirou "o termo ideologia de gênero" em sua versão final e que, ainda que reconhecendo que a discriminação permeie o ambiente escolar, não haveria justificativas para "difundir a ideia de que o homem nasce um ser andrógino", considerando que isso seria "desfaçatez de uma minoria para transformar o moral no imoral". Também compôs a 
justificativa o fato de que o PEE e o PME não inseriram "ideologia de gênero" em seus textos aprovados e na Câmara Municipal de Manaus "foi necessário que a bancada evangélica interviesse para retirar o termo que nem o Plano Nacional ou Estadual abordou". Há no argumento da justificativa a afirmação de que trabalhar tais conteúdos seria fazer "a defesa de um comportamento de minoria", motivado por "uma orientação político partidária para a desestruturação da comunidade, que reconhece que os dois sexos, masculino e feminino, não são construções culturais e sociais".

O texto da justificativa é rico em elementos que evocam a moral religiosa como motivação legislativa, aparentes nos debates e conflitos suscitados a partir do PME e que possibilitaram a proposição do PL em questão. Ademais, sabemos, nas Ciências Humanas e Sociais, que o termo minoria tem sido forjado acadêmica e politicamente para denunciar a exclusão de segmentos sociais historicamente invisibilizados, sem pleno acesso a cidadania e não reconhecidos em sua identidade. O termo, portanto, não expressa uma medida quantitativa, mas designa e denuncia condições históricas e estruturais de exclusão social experimentada por coletividades.

Como nossas interlocutoras ressaltam, o Ediversa, que reúne lideranças LGBT, pesquisadores, educadores, profissionais de diferentes áreas e ativistas/militantes de movimentos sociais em defesa da diversidade, do respeito às diferenças e contra as violências de gênero na educação, foi fundamental para a resistência no Amazonas. Como ação desse movimento, foi produzida uma carta aberta, entregue na Câmara Municipal de Manaus em contraposição ao PL citado.

Em agosto de 2016, foi protocolada junto aos Ministérios Públicos Federal e Estadual, Defensorias Públicas do Amazonas e da União e na Câmara Municipal de Manaus um conjunto de documentos, alegando a inconstitucionalidade do PL, que contou com a adesão de mais de 400 assinaturas.

Embora a articulação do Ediversa tivesse provocado alguma reflexão pública em torno do tema entre a sociedade civil e nas universidades e tenha sido destacado na imprensa local, o mesmo não aconteceu na Câmara Municipal. O projeto tramitou por todas as comissões e foi aprovado em março de 2017.

Portanto, os enfrentamentos iniciados nas discussões acerca do Plano Estadual de Educação, passando pela articulação de setores conservadores (majoritariamente religiosos) e da bancada evangélica na Câmara Municipal de Manaus, foram bastante eficazes no sentido de suprimir qualquer menção à não discriminação de gênero e orientação sexual e de não fomentar que a educação contemple as diversidades sexuais e de gênero. Tais resoluções permitiram que surgisse no legislativo municipal a motivação e força para a aprovação de uma lei proibitiva, cujos efeitos ainda estão em análise, pois a disputa em torno da revogação da lei ainda não está encerrada. Esse antagonismo revela que o significado de gênero e sua importância nas políticas educacionais ainda estão em disputa. 
As iniciativas e debates propostos pelo Ediversa suscitaram o debate público e o grupo protocolou nos Ministérios Públicos Federal e Estadual (MPF e MPE), nas Defensorias Públicas do Amazonas e da União (DPE e DPU) e também na própria Câmara Municipal um conjunto de documentos formados por 20 artigos científicos e artigos de lei que, segundo eles, comprovam a inconstitucionalidade do PL. Mais 400 assinaturas acompanham os documentos, dentre eles uma "Contestação ao Projeto de Lei n⿳ํㅡㄹ 389/2015" e o texto de subsídios As teorias de gênero e sexualidade e sua importância na educação . Como consequência, em julho de 2017, o Ministério Público Federal (MPF) publicou uma recomendação, contestando a lei municipal, notificando as secretarias municipal e estadual de educação para que promovam e conscientizem professores a continuarem com ações pedagógicas sobre gênero. A recomendação considera a educação um direito fundamental e que a Lei 439/2017, "viola frontalmente a liberdade de aprender, expressar-se, ensinar, pesquisar e divulgar o pensamento, a arte e o saber, bem como o respeito ao pluralismo de ideias e concepções pedagógicas" referindo-se a Constituição Federal de 1988. Um argumento interessante da recomendação é que a referida lei,

\begin{abstract}
condena os educandos ao desconhecimento e à ignorância sobre uma dimensão fundamental da existência humana, impedindo que a educação desempenhe seu papel fundamental de transformação cultural e promoção da igualdade sobre o prisma da dignidade humana, o que representa descumprimento das decisões do STF. Cita a carta Magna como documento que garante a igualdade entre homens e mulheres, convenções internacionais.
\end{abstract}

Da mesma forma a recomendação confere seu entendimento sobre o conceito de gênero, considerando que este

está atrelado a dimensão de construção social, política, histórica de sentidos e significados para a distinção e aproximação entre homens e mulheres, femininos e masculinos, feminilidades e masculinidades, e o termos orientação sexual está relacionado à sexualidade humana.

Considera ainda que a transexualidade e a homossexualidade são fatos da vida que não deixarão de existir por sua negação e independem de querer ou ensinamento das pessoas, sendo a educação principal instrumento de superação da incompreensão, do preconceito, da intolerância que acompanham esses grupos ao longo de suas vidas. Tal recomendação, na prática, sintetiza os argumentos expostos pelo Ediversa no documento que contestava o PL 389/2015 e questionava ponto a ponto a justificativa ao Projeto de Lei. Em maio de 2018, o Tribunal de Justiça do Amazonas (TJAM) suspendeu os artigos primeiro e segundo da Lei, por unanimidade, acompanhando o voto da relatora.

Foi noticiado no próprio site do TJAM a Medida Cautelar em Ação Direta de Inconstitucionalidade (ADI), ajuizada pelo Ministério Público Federal do Amazonas (MPF), segundo o qual “os dois artigos contrariam a Constituição Estadual, violando 
princípios básicos da educação e do sistema educacional do Amazonas. [...] Entre as diretrizes educacionais [da] Constituição do Estado do Amazonas de 1989, figuram os princípios da democracia, da liberdade de expressão e do respeito aos direitos humanos, bem como o fomento à 'elaboração e reflexão crítica da realidade' e ao 'exercício da cidadania', com vistas 'ao pleno desenvolvimento da pessoa' ". ${ }^{8}$

Na ocasião o MPF também se manifestou, argumentando que os dois dispositivos da Lei "afrontam e tornam vulneráveis" os princípios da dignidade da pessoa humana, previstos na Constituição Federal (art. $1^{\circ}$, III), e do estado democrático de direito (art. $1^{\circ}$, caput, CF), além de impedir, no ambiente escolar, a diversidade de valores, crenças e opiniões e, ainda, o pluralismo na liberdade de manifestações.

A Câmara Municipal de Manaus defendeu o indeferimento da medida liminar. Já a Procuradoria-Geral do Município requereu o reconhecimento da existência de vício formal dos dispositivos. A Procuradoria-Geral do Estado manifestou-se pela não oposição ao deferimento da medida liminar. A ação tramitou no TJAM, que julgou pela revogação da lei. Em final de 2019, a Câmara recorreu ao Supremo Tribunal Federal, que, em janeiro de 2020, julgou a inconstitucionalidade da Lei. ${ }^{9}$

Esse complexo contexto em Manaus, brevemente descrito aqui, "de dentro do olho do furacão", perpassa controvérsias no campo de gênero e educação nas esferas nacionais e transnacionais. No âmbito nacional, evidencia algumas questões em torno de gênero e dos direitos humanos no Brasil. A partir dos documentos elaborados e enviados pelo Ediversa na esfera estadual e federal do Ministério Público, a visibilidade em torno dos atos e a intensa dedicação do grupo, bem como o movimento em outras regiões do País ${ }^{10}$, não podemos tomar o caso de Manaus como isolado. As ações e práticas sociais são fundamentais para a consolidação dos Direitos Humanos no Brasil, como aponta o antropólogo Theophilos Rifiotis. O autor chama a atenção também para o modo como tais sujeitos se apropriam dos aspectos jurídicos para a efetividade de seus direitos (RIFIOTIS, 1994).

É fundamental que possamos refletir que os múltiplos usos e disputas em torno do gênero, especialmente quando transpõem os estudos de gênero para outras esferas, distorcendo suas concepções e constituindo expressões falaciosas como "ideologia de gênero", têm um caráter reativo conservador que precisa ser analisado em termos da política e do poder. Sob o discurso político de que a "ideologia de gênero" ameaça a família é que se sustentam posições reacionárias, opositoras dos direitos humanos, segundo as quais "ameaçam a família natural” (JUNQUEIRA, 2017).

A definição de família desses grupos é, portanto, descritiva e prescritiva: homem e mulher como base. No entanto, embora possamos considerar a família como base da sociedade, não é possível afirmar apenas uma configuração de família. Família pressupõe não apenas laços sanguíneos, mas laços de apoio emocional e afetivo, importante no processo de socialização. Novas modalidades de família e novas tecnologias reprodutivas têm reiteradamente mostrado que família tem inúmeras possibilidades de configuração; 
é, portanto, necessário que se reconheça e defina família não pelos sujeitos que a compõem, mas pelas relações que se estabelecem, assim, os novos laços contemporâneos de afeto e solidariedade podem ser incorporados à esta noção.

Cabe, ainda, ressaltar que "ideologia de gênero" nunca foi um termo amplamente utilizado nos estudos de gênero e sexualidade no Brasil, embora tenha sido utilizado com o objetivo de expor como pensamentos dominantes reificam desigualdades de gênero.

A expressão "ideologia de gênero" foi acionada pelos discursos conservadores de modo a esvaziá-lo de sentido. Ideologia de gênero passa, assim, a ser um conceito que, por um lado, denomina uma suposta estratégia de "destruir a família" (no singular) e fazer "doutrinação gay", estopim para "pânico moral", agregando setores para além dos religiosos e mobilizando a sociedade em seu combate. E, por outro lado, reforça a eficácia das ideologias dominantes no que diz respeito à família, ao sexo, ao gênero e às hierarquias e lugares de poder.

Ao longo de quatro anos foram se evidenciando alguns resultados do processo iniciado em 2015 pelo Ediversa em diferentes formatos, como a recomendação do Ministério Público Federal às secretarias estadual e municipal de educação para que se mantivessem as discussões e ações voltadas à equidade de gênero e, por fim, a suspensão da Lei promulgada, baseada em sua inconstitucionalidade. As discussões jurídicas sobre leis parecidas em outros estados do Brasil argumentam sempre sua inconstitucionalidade a partir da quebra de preceitos fundamentais e que, além de considerar os aspectos legais, os aspectos sociais também são importantes para a "correta aplicação do direito" (SILVEIRA, et. al, 2000). Nas Ciências Humanas e Sociais, observamos o processo de "judicialização das relações sociais" e apropriação dos sujeitos sobre os aspectos jurídicos; neste caso, os sujeitos são tanto propriamente da vida política/militância LGBT quanto da vida acadêmica/ciência em fluidas fronteiras.

Recebido em: 09/06/2020 e Aprovado em: 24/06/2020

\section{Notas}

1 Entrevista com FL, antropóloga, professora da UFAM. Realizada em março de 2018.

2 Entrevista com MI, travesti, estudante de História. Realizada em maio de 2018.

3 A historiadora Mônica Lima, ao pensar a história da África no Brasil e a importância da lei acima citada, admite que "estamos conscientes de que não se educa apenas em sala de aula. Mas a escola e a universidade ainda são lugares de grande influência na formação de posturas e visões de mundo. E igualmente não podemos estar seguros de que a introdução dos estudos sobre a História da África e do negro no Brasil garantam uma mudança, mas ao longo do tempo de ausência e negação dessas histórias certamente contribuiu para fortalecer o preconceito e a intolerância que tanto queremos combater". LIMA, Mônica. "Aprendendo e ensinando his- 
tória da África no Brasil: desafios e possibilidades" In: ROCHA, Helenice Aparecida Bastos; MAGALHÃES, Marcelo de Souza; GONTIJO, Rebeca (Orgs.). A escrita da história escolar: memórias e historiografia. Rio de Janeiro: Editora FGV, 2009.

4 Entrevista com TA, estudante de História. Realizada em abril de 2018.

5 Documentos disponíveis no site da Associação Brasileira de Antropologia (ABA).

6 Uma busca no site do Conselho Federal de Psicologia com a palavra "gênero" mostra 236 resultados de matérias envolvendo a participação do Conselho em diversas discussões e ações que envolvem gênero, educação e direitos, entre eles: Direitos humanos sobre diversidade sexual e de gênero, direito das pessoas LGBTIQ+, enfrentamento à violência contra a mulher, aborto, contrariedade à aprovação do Escola Sem Partido, à imposição da agenda moral sobre a agenda sexual, violência nas escolas, discussão interseccional das diferenças, abuso e exploração de crianças e adolescentes, educação inclusiva, entre outros. Disponível em: https://site. cfp.org.br/. Acesso em: 24 de abril de 2019

7 PL 389/2015, proposto pelo vereador Marcel Alexandre. “Proíbe na grade curricular das escolas do município de Manaus, as atividades pedagógicas que visem à reprodução do conceito de ideologia de gênero"

8 "Justiça declara inconstitucionalidade de lei que vedava a reprodução do conceito de ideologia de gênero em escolas da SEMED." Disponível em: https://www.tjam.jus.br/index.php/menu/sala-de-imprensa/1226-justica-declara-inconstitucionalidade-de-lei-que-vedava-a-reproducao-do-conceito-de-ideologia-de-genero-em-escolas-da-semed. Acesso em: 09 de junho de 2020.

9 "STF confirma acórdão do TJAM que declarou inconstitucional lei municipal que vedava a reprodução do conceito de ideologia de gênero". Disponível em: https://www.tjam.jus.br/index.php/menu/sala-de-imprensa/2430-stf-confirma-acordao-do-tjam-que-declarou-inconstitucional-lei-municipal-que-vedava-a-reproducao-do-conceito-de-ideologia-de-genero-em-escolas-da-semed. Acesso em: 09 de junho de 2020.

10 Vale lembrar que a contestação percebida, além de ocorrer em âmbito nacional, também enfrenta um movimento que ocorre em outros países da América Latina e se aglutinam a outras nuances do conservadorismo, que atacam também a democracia. REIS, Toni. Gênero e LGBTfobia na Educação. In: A Ideologia do movimento Escola sem Partido. 20 autores desmontam o discurso. Ação Educativa Assessoria, Pesquisa e Informação (Org.). São Paulo: Ação Educativa, 2016.

\section{Referências}

CARRARA, Sérgio. A antropologia e o processo de cidadanização da homossexualidade no Brasil. Cadernos Pagu. Campinas n. 47, v. 17, p.445-482, novembro de 2016.

EDIVERSA. As teorias de gênero e sexualidade e sua importância na educação. Manaus: Ediversa, 2016.

EDIVERSA. Contestação ao Projeto de Lei no 389/2015. Manaus: Ediversa, 2016.

JUNQUEIRA, Rogério Diniz. "Ideologia de Gênero": a gênese de uma categoria política reacionária ou: a promoção dos direitos humanos se tornou uma "ameaça à família natural"? In: RIBEIRO, Paula Regina Costa; MAGALHÃES, Joanalira Corpes (Org.). Debates Contemporâneos sobre Educação para a Sexualidade. Rio Grande. Ed. da FURG, 2017. p.25-52

LIMA, Mônica. Aprendendo e ensinando história da África no Brasil: desafios e possibilidades. In: ROCHA, Helenice Aparecida Bastos; MAGALHÃES, Marcelo de Souza; GONTIJO, Rebeca (Orgs.). A escrita da história escolar: memórias e historiografia. Rio de Janeiro: Editora FGV, 2009. p.149-164.

MATOS, Marlise. Teorias de gênero ou teorias e gênero? Se e como os estudos de gênero e feministas se transformam em um campo novo para as ciências. In: Estudos Feministas, Florianópolis, n. 2, v. 16, p. 333-357, maio-agosto/2008. 
REIS, Toni. Gênero e LGBTfobia na Educação. In: A Ideologia do movimento Escola sem Partido. 20 autores desmontam o discurso. Ação Educativa Assessoria, Pesquisa e Informação (Org.). São Paulo: Ação Educativa, 2016. p.117-124

RIFIOTIS, Theophilos. Judicialização dos Direitos Humanos, lutas por reconhecimento e políticas públicas no Brasil: configurações de sujeito. Revista de Antropologia, São Paulo, v.57, n.1, pag. 119-144, novembro de 2014.

ROTONDANO, Érica Vidal. Trabalho de Formiguinha: formação continuada de docentes em sexualidade na rede municipal de educação em Manaus. Tese de doutorado. Instituto de Medicina Social, Universidade do Estado do Rio de Janeiro e Universidade do Estado do Amazonas, Rio de Janeiro, 2019.

SILVEIRA, Gabriel Eidelwein et al. Judicialização e "ideologia de gênero": a proibição dos estudos de gênero na escola e a ação cabível. Brazilian Journal of Development, Curitiba, v.6, n.4, p.17450-17463, apr. 2020. 